\title{
GOVERNMENT SUBSIDIES IN PUBLIC-PRIVATE PARTNERSHIP PROJECTS BASED ON ALTRUISTIC THEORY
}

\author{
Yinglin WANG ${ }^{1}$, Jicai $\mathrm{LIU}^{2}$, Ruolan $\mathrm{GAO}^{2, *}$, Bon-Gang HWANG ${ }^{3}$ \\ ${ }^{1}$ Department of Transportation and Civil Engineering, Fujian Agriculture and Forestry University, Fuzhou, China \\ ${ }^{2}$ School of Economics and Management, Southwest Jiaotong University, Chengdu, China \\ ${ }^{3}$ Department of Building, National University of Singapore, Singapore, Singapore
}

Received 26 March 2019; accepted 06 November 2019

\begin{abstract}
Nowadays, the public-private partnership (PPP) scheme has been widely adopted in infrastructure projects around the world. In PPP projects, the governments participate as a principal and the investors play the role of an agent, and therefore their behaviours and incentive strategies can be explained and designed by the principal-agent theory. As "economic men" with limited rationality, both the governments and the investors have altruistic preferences during cooperation. This paper studies how project participants' altruistic preferences affect government subsidies based on the principal-agent theory. To this end, a principal-agent model in the presence of altruism is developed. The results show that the amount of government compensation is related to the altruistic preferences, the expected revenue, costs and investors' efforts. Contrary to intuition, the governments' altruism actually undermines the investors' enthusiasm in cooperation and the risk-sharing propensity, although it increases the utilities of both parties. Moreover, when selecting the investors, governments should examine their operating capacity carefully, which has a significant impact on the sustainable development of the projects and even PPP arrangements. The findings contribute new insights into the development of incentive mechanisms between governments and private investors from the perspective of the behavioural preferences.
\end{abstract}

Keywords: public-private partnership projects, government guarantee, principal-agent theory, altruistic theory, risk-sharing, subsidies.

\section{Introduction}

Public-private partnership (PPP) arrangements have gained worldwide popularity in the provision of public services and products, such as plants, highways and tunnels (Song, Zhao, Jin, \& Sun, 2018). Generally authorized by the governments, private investors recover their investment mainly through user payment (for instance, toll revenue) during the operation stage of these PPP projects (Feng, Zhang, \& Gao, 2015). However, the infrastructure projects are fraught with risks (e.g., demand risk and force majeure risk etc.), which results in great uncertainties with regard to achieving the investors' expected rate of return (Wang, Gao, \& Liu, 2019). Since PPP projects usually present strong public welfare and poor profitability, investors may not acquire reasonable profits only through the operation revenue, which even cannot cover the operation cost. In this scenario, governments should provide some substantial economic subsidies as specified in the concession agreement agreed upon by both parties to ensure PPP projects commercially viable
(Song et al., 2018; Soumaré, 2016; Sun \& Zhang, 2014; Wang, Cui, \& Liu, 2018; Xu, Yeung, \& Jiang, 2014). By the end of June 2019, there are 8414 projects with government subsidies in China alone, accounting for 93.1\% (Ministry of Finance of the People's Republic of China, 2019).

From the perspective of the traditional economic theory, the most fundamental duty of the investors shall be accountable to all shareholders, and their original goal is to derive the maximum profits, which is no exception for private investors of PPP projects (Wang \& Liu, 2015). Nonetheless, more and more economists have pointed out that the profits for the investors consist of not only the direct profits of projects, but also some invisible benefits from achieving social benefits and enhancing corporate value. In the late 1990s, Carroll (1991) proposed a hierarchical responsibility model for corporate social responsibility (CSR), indicating that investors hold economic and legal responsibilities, as well as ethical and charitable responsibilities. In PPP projects, based on the completion of the basic economic activities, altruism helps investors

*Corresponding author. E-mail: rlangao@126.com 
develop good political relations with governments and attract the attention of the media to promote the corporate image (Borghesi, Houston, \& Naranjo, 2014). More importantly, appropriate altruistic preferences are conducive to improve the project efficiency, thus creating additional external values for both governments and investors (Dur \& Tichem, 2015; Ge, Zhang, Lü, Zhou, \& Xi, 2012).

Although the original motive of economic philanthropy is self-interests rather than altruism, the practical results show that this kind of non-subjective altruism has achieved a win-win situation between enterprises and recipients ( $\mathrm{Ge} \& \mathrm{Hu}, 2012$ ). Compared with the profitable projects using other schemes, the investment return of PPP projects is typically lower. But these projects usually bring benefits to the society in terms of environment, employment, medical care and transportation etc., further improving the social value of private investors and ultimately contributing to maximizing profits (Moore, Boardman, \& Vining, 2017; Wu et al., 2018). Therefore, the appropriate government subsidies for investors based on altruistic theory helps to encourage them to bear the social responsibility forwardly and obtain indirect benefits.

According to the contractual relationship in PPP projects, the governments participate as a principal and investors play the role of an agent. Thus, their behaviours and incentive strategies can be explained by the principal-agent theory. Using this theory, the primary objective of the paper is to construct a government subsidy model (i.e. the distribution of government guarantee option value) based on altruistic theory to provide a reference for both governments and private investors. This paper is organized as follows. First, an overview of the government subsidies in PPP projects and altruistic theory is presented. Then, an optimal government subsidy model for the governments and the investors with altruistic preferences is developed, followed by an equilibrium solution. Next, results and implications from this model are discussed. Specifically, a numerical simulation is presented and the results of this simulation are examined to illustrate the theoretical application of this model. Finally, the research closes with certain conclusions drawn. Exactly, the contribution of the article is to integrate altruistic theory with principal-agent theory to address the issue of government subsidies for private investors in PPP projects. This incentive mechanism is conductive to curb opportunistic behaviour of private investors, promoting the governance efficiency and sustainable development of PPP schemes. The findings stimulate questions about how different degrees of altruistic preferences might impact optimal government subsidies for both governments and private investors in PPP projects.

\section{Literature review}

\subsection{Government subsidies in PPP projects}

Fraught with many risks (e.g., construction risk and demand risk, etc.) that may or may not materialize in the future, the actual revenue obtained by private investors may be less than the estimated one (Wang et al., 2019). Consequently, private investors cannot reap reasonable profits and even become entangled in losses. When the actual revenue of investors is lower than a pre-specified threshold as agreed in the contracts, governments should compensate the investors for the difference between the estimated and the actual revenue, i.e. the government guarantee. In terms of such government guarantee, investors can receive a certain level of subsidies. Specifically, government subsidies present many forms in practice worldwide, such as direct investment grants etc. (Shi, Yin, \& Guo, 2016). In addition, governments can arrange free allocation of land use right and grant franchise of the surrounding land and commerce, as well as concessional loans, loan interest subsidies and the give-up of dividends of the government-occupied shares (Feng et al., 2015; Marzouk \& Ali, 2018). By nature, government subsidies aim to effectively reduce the construction and operation costs to mitigate the risks and further improve the economic profits to ensure the commercial feasibility of PPP projects (Almassi, McCabe, \& Thompson, 2012).

Subsidies provided by governments in PPP projects amounts to a risk sharing mechanism for project returns to some degree (Wibowo et al., 2012). Instead, the governments share the revenue risk by providing guarantees, including concession guarantees (Carbonara, Costantino, \& Pellegrino, 2014a; Galera \& Soliño, 2010), services or products purchasing guarantees (Zhang, Chan, Feng, Duan, \& Ke, 2016), restrictive competition guarantees (Liu, Yu, \& Cheah, 2014), price adjustment guarantees (Carvalho \& Nechio, 2011), minimum demand guarantees (Feng et al., 2015; Song et al., 2018; Wang et al., 2019), price compensation guarantees (Liu, Gao, \& Cheah, 2017; Xiong, Zhang, \& Chen, 2015), and minimum revenue guarantees (MRG) (Buyukyoran \& Gundes, 2018; Carbonara \& Pellegrino, 2018; Carbonara, Costantino, \& Pellegrino, 2014b). However, too much risk-taking will eventually lead to government debt beyond payment capacity, thereby causing frequent local government defaults and even thorough failures of PPP projects. In those failure cases of PPP projects in the worldwide, the governments have provided guarantees for investors' minimum profits (Song et al., 2018; Wang et al., 2018, 2019). Contrary to intuition, excessive government guarantees will lead to unreasonable risk sharing, increasing project risks instead (Xu et al., 2014). Thus, a reasonable risk allocation mechanism is important to enhance the willingness to cooperate and guide private investors in decision-making behaviour, and has also a positive impact on the improvement of the project performance.

The core principle of risk allocation is to ensure that the risk-bearing parties can control these risks best (Nasirzadeh, Khanzadi, \& Rezaie, 2014). The approaches of risk distribution can be categorized into qualitative and quantitative analysis. Qualitative analysis focuses on matching the risk attributes with the risk-taking capacities of all parties to determine a proper allocation mech- 
anism (Ke, Wang, \& Chan, 2010a). However, quantitative analysis is aimed to solve for an optimal proportion of risk allocation among different parties to maximise the efficiency from the perspective of the whole projects (Alonso-Conde, Brown, \& Rojo-Suarez, 2007; Fahad AlAzemi, Bhamra, \& Salman, 2014; Jin \& Zhang, 2011; Nasirzadeh et al., 2014; Pellegrino, Ranieri, Costantino, \& Mummolo, 2011).

As shown in Figure 1, with the increased risk sharing by private investors, the project efficiency improves and the total project costs decline gradually, signifying the value for money (VfM) is increasing (from "a" to "b"). Nevertheless, when the transferred risks exceed a certain level (point " $b$ "), projects efficiency begins to decline (Ke, Wang, Chan, \& Lam, 2010b). The shaded area is the rational risk allocation area, and proportions of risk allocated to investors are from point "a" to point "c". In order to achieve the maximum profits, "b" value needs to be determined.

Generally, existing researches on the distribution and incentive of cooperative profits assume decision-makers as economic man, while ignoring the different personalities of these decision-makers and the complexity of their behaviours. This assumption restricts its explanatory power to practical problems (Loch \& Wu, 2008). With the development of behavioural theory, more scholars have realized that individuals actually exist as "social beings", indicating that the decision-makers typically have feelings of altruism (Dur \& Tichem, 2015; Gino \& Pisano, 2008). When making decisions regarding cooperative behaviours, both governments and private investors are not entirely self-interested, but also influenced by their own altruistic preferences, which should be paid more attention when allocating the risks in PPP projects. Thus, the objective of this paper is to analyse the optimal risk distribution mechanism, i.e. the optimal government subsidies provided to private investors using principal-agent theory and altruistic theory approach. The introduction of such behavioural preferences into cooperation between the two parties will help to remedy the limitations of the existing theoretical researches in PPP arrangements (Wang \& Liu, 2015).

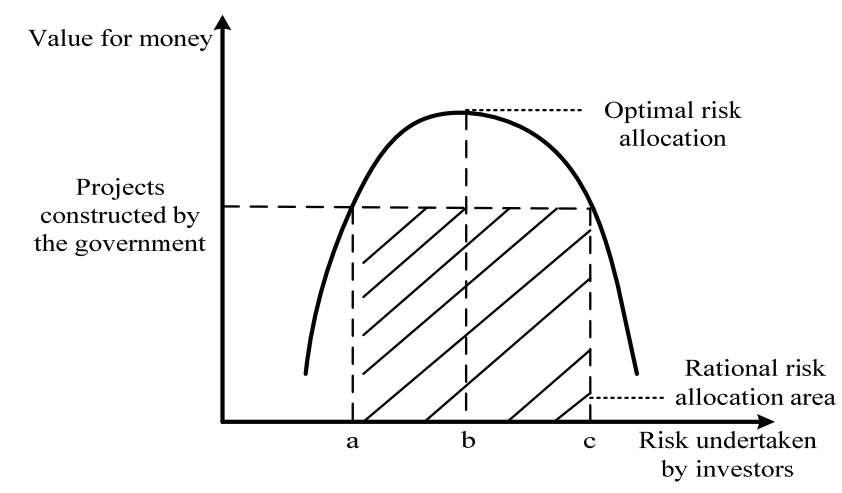

Figure 1. Risk allocation effects on the monetary value

\subsection{Altruistic theory}

Behavioural economics and social psychology demonstrate that when making decisions, human beings not only pay attention to their own profits, but also to the profit level of others and the fairness of the profit distribution. That means people generally have fairness and altruistic preferences rather than only self-interested preferences. Importantly, these psychological preferences can significantly affect the decision-making behaviours (Gino \& Pisano, 2008; Loch \& Wu, 2008). The social preferences systematically trigger emotions and that altruistic preference is an important determinant affecting decision-making utility and individual behaviour (Urda \& Loch, 2013). The probabilities of cooperation positively correlate with players' altruism (Kułakowski \& Gawroński, 2009).

Human altruism is such a powerful and unique power that a few altruists can force most selfish individuals to cooperate (Fehr \& Fischbacher, 2003). Evolutionary theory postulates that altruistic behaviour evolved for the return-benefits it bears the performer (De Waal, 2008). That is, behaviourally, altruism is any act that can have resulted from altruistic motivations (Elster, 2006). However, Nandavar, Lewis, and White (2019) believes that no act is performed without a motivation. Therefore, altruism can be understood in a psychological sense, which motivationally can be treated as the desire to enhance the welfare of others at a net welfare loss to oneself (Elster, 2006). Taking the classical prisoners' dilemma game as an example, the players have clearly expressed an interest in behaving altruistically, from which the players always expect to personally benefit in some way. Through experiments conducted by Andreoni and Miller (2002), the price and income variation creates budgets for altruistic activity to test for an underlying preference ordering. And Andreoni and Miller (2002) further confirmed the rationality of altruism, which can be understand sufficiently by an economic model.

Nowadays, most researches concerning altruistic preferences have focused on the many fields, such as supply chain (Ge \& Hu, 2012), behavioural decision-making (Nandavar et al., 2019) and the carbon market (Salas \& Roe, 2012) etc. For instance, $\mathrm{Ge}$ and $\mathrm{Hu}$ (2012) interpreted firms' cooperative incentive as their altruism, and pointed out that a manufacturer with altruistic liability would benefit both the supply chain and the retailers. Also, the performances and the efficiency of supply chain with altruistic attributes are significantly improved (Ge et al., 2012; Hosoda \& Disney, 2006), and both the optimal wholesale and retail price are affected (Shi, Jiang, \& Ouyang, 2013). Recently, a competitive - cooperative strategy with altruism proposed indicates that only offline retailers have entirely altruistic behaviour (Xu \& Wang, 2018). In the respect of guiding behaviour in transportation, such altruistic behaviours may help to create a more positive and harmonious driving context to improve road safety ultimately (Nandavar et al., 2019). Differently, more studies have focused on altruism of parties with the principal- 
agent relationship. Salas and Roe (2012) designed relational contracts between a selfish agent and an altruistic principal, revealing that the principal's altruism increases with the higher credibility of the bonus. Compared with the more self-interested principals, the presence of an altruistic principal increases the likelihood of cooperation in the long-term relationship (Salas \& Roe, 2012). Given the assumption of some altruistic and unobserved fraction of agents, long-term relational contracts will further generate high effort levels, exhibit rent sharing, and punish low effort with dismissal (Brown, Falk, \& Fehr, 2004, 2012). Dur and Tichem (2015) also developed a simple dynamic principal-agent contract containing two types of incentives for the agents: a bonus and a threat of dismissal. Instead, altruistic behaviours are usually executed in the absence of reward anticipation (Piliavin, 2009). To conclude the above literature review, altruistic preferences definitely have a positive impact on the outcomes and effectiveness as well as the distribution of profits. Essentially, altruism is reciprocal for all participants.

The mutual cooperation, between governments and private investors in PPP projects, exactly requires altruism of both parties. Nevertheless, few studies have paid attention to the analysis of altruistic theory in such PPP projects. Through PPP contracts, private investors are authorized to finance, build, operate and maintain the projects, and bear the duty for providing public services or products; whereas governments subsidize those projects by sharing the risks with investors to reap reasonable profits (Almassi et al., 2012; Song et al., 2018; Wang et al., 2019). Such trading behaviour between governments and private investors can also be explained by altruism theory. The governments' altruism can impact the terms of trade in PPP market, while more self-interested investors to profit maximizing with a tendency to rent seeking and corruption will be less likely to achieve cooperation. As a result, the altruism enhancement of the two parties is an effective way to improve the cooperation efficiency in PPP projects. Different from the existing studies to analyse the overarching concept of altruism through descriptive or explanatory research, this paper believes that altruism is a stable personality trait and can be comprehended by some attempts. Additionally, both governments and private investors have feelings of altruism. That is, governments and private investors are unconditionally altruistic, and the degree of their altruistic preferences can be observable in PPP projects. Therefore, this paper will construct a principal-agent model to formulate the optimal government subsidy mechanism based on the altruistic preferences of both parties.

\section{Government subsidies model based on altruistic theory}

For the PPP projects with the return mechanisms of government subsidies, as illustrated in Figure 2, there is a difference $(\Delta \pi)$ between the investors' estimated revenue $\left(\pi_{e}\right)$ and the real one $\left(\pi_{r}\right)$. Specifically, $\pi_{e}$ is defined as the

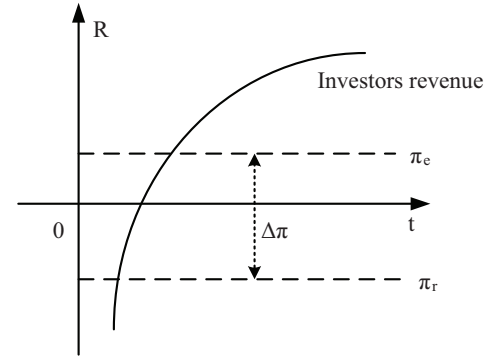

Figure 2. Difference between investors' estimate and real revenue

average revenue that the investors could receive when they participate in other projects. If the governments pay for the entire shortfall $(\Delta \pi)$, then they effectively take over all the investors' revenue risk. Obviously, this burden should be shared between both two parties. Typically, the government guarantees are valuable and can be estimated by some techniques such as real option (Cheah \& Liu, 2006). The distribution of the guarantee value is the flipped side of risk allocation. For the governments, the higher the share of this value they own, the lesser is the risk that they are burdened with. By the same token, the investors are also faced with a similar concern.

In the principal-agent model, an agent's efforts and performance are often difficult to verify, and thus the moral hazard may occur. For instance, if the governments allocate too many risks to private investors during the negotiation stage, investors' enthusiasm for the project might be negatively impacted. Then, investors might reduce their level of productive efforts, such as intentionally keeping their real revenue below the estimated threshold to secure more guarantee value. Alternatively, they might cut down on their facility maintenance efforts, such as reducing the required refurbishment and upgrading of equipment and technology. As a result, the lower efforts usually lead to a lower performance of the facility during the operation stage or even when handed over at the end of the concession. Therefore, a proper risk sharing mechanism needs to be designed to reduce the government financial pressure and motivate the investors to expend a high level of efforts in the project. The difference between the estimated and real revenue $\left(\pi_{e}-\pi_{r}\right)$ is exactly the value shared by two parties. The subsidy ratio provided by the governments is $p$, and accordingly the profit-sharing rate of governments is $(1-p)$. The obtained value by the investors consists of two parts: earned from their efforts and the subsidy provided by the governments. Without considering the players' altruistic preferences, the governments' and the investors' revenue are expressed respectively as follows:

$$
\begin{aligned}
& R_{1}=(1-p) \times\left(\pi_{e}-\pi_{r}\right) ; \\
& R_{2}=a+p \times\left(\pi_{e}-\pi_{r}\right)-C,
\end{aligned}
$$

where: $a$ is the efforts expended by the investors, and $C$ is operation cost paid during the operation stage. Generally in PPP projects, the operation cost $(C)$ and actual revenue 
$\left(\pi_{r}\right)$ are correlated with the level of investors' efforts $(a)$, and thus $C$ and $\pi_{r}$ can be respectively denoted as $C(a)$ and $\pi_{r}(a)$. Based on the principal-agent theory, the agent's effort cost is $C(a)=\frac{1}{2} b a^{2}$, where $b$ is the cost coefficient for effort expended and $b>0$ (Holmstrom \& Milgrom, $1987)$. For ease of discussion, assume the revenue $\left(\pi_{r}\right)$ of PPP projects is linear with the investors' efforts contributed, that is $\pi_{r}(a)=a+\theta$, where $\theta$ is a random variable of a normal distribution and $\theta \sim N\left(0, \sigma^{2}\right)$. Then, the expected utility of the governments and the investors without considering altruism are represented respectively by $U_{1}$ and $U_{2}$ as follows:

$$
\begin{aligned}
& U_{1}=E\left(R_{1}\right)=(1-p) \times\left(\pi_{e}-a\right) ; \\
& U_{2}=E\left(R_{2}\right)=a+p \times\left(\pi_{e}-a\right)-\frac{1}{2} b a^{2} .
\end{aligned}
$$

Generally, a self-enforcing contract is more preferred and effective compared to a strict one imposed upon via legal and regulatory means. However, the inherent selfrestraint of project parties has a positive impact on project efficiency improvement (Hosoda \& Disney, 2006). Therefore, the parties' altruistic preferences should be considered when designing contracts. Considering both the governments' and the investors' behaviours are affected by their altruistic preferences, then their expected utilities are changed to $U_{1}^{*}$ and $U_{2}^{*}$ as follows (Loch \& Wu, 2008):

$$
\begin{aligned}
& U_{1}^{*}=U_{1}+\varepsilon_{1} U_{2} ; \\
& U_{2}^{*}=U_{2}+\varepsilon_{2} U_{1},
\end{aligned}
$$

where: $\varepsilon_{1} U_{2}$ and $\varepsilon_{2} U_{1}$ denote the altruistic utilities of the governments and the investors; $\varepsilon_{1}$ and $\varepsilon_{2}$ are respectively the governments' and the investors' altruism, and $\varepsilon_{1}, \varepsilon_{2} \in[0,1]$.

In the ideal case, both the attitudes toward risks of governments and private investors can be comprehended based on the previous PPP projects that they have participated in. More attempts, such as questionnaire, can be made to calibrate for the altruistic preferences. That is, altruistic preferences of the governments $\left(\varepsilon_{1}\right)$ and investors $\left(\varepsilon_{2}\right)$ can be assessed. In this scenario, substituting Eq. (2) into Eq. (3), their expected utilities with altruistic preferences can be expressed as follows:

$$
\begin{aligned}
& U_{1}^{*}=(1-p)\left(\pi_{e}-a\right)+\varepsilon_{1}\left[a+p\left(\pi_{e}-a\right)-\frac{1}{2} b a^{2}\right] ; \\
& U_{2}^{*}=a+p\left(\pi_{e}-a\right)-\frac{1}{2} b a^{2}+\varepsilon_{2}(1-p)\left(\pi_{e}-a\right) .
\end{aligned}
$$

To sum up, the definitions of these relevant parameters are as follows in Table 1.

Comparing Eqs. (2) and (4), both the utilities of the governments and investors with altruism increase. This implies that their altruistic preferences create positive incentives during the cooperation. For private investors, participating in PPP projects can help them establish positive images and obtain higher market exposure and visibility, which will indirectly improve their marginal benefits and further achieve the economic objectives; whereas for the governments, not only will altruism attract more investments from private investors, but also will encourage investors to invest a high level of efforts, which as a result effectively increases social benefits without aggravating the financial burden. The change in investors' revenue based on their altruism is shown in Figure 3.

As the governments represent the public's interest, their

\begin{tabular}{|c|c|}
\hline Symbols & Definitions \\
\hline$R_{1}$ & The revenue of the governments \\
\hline$R_{2}$ & The revenue of the investors \\
\hline$p$ & $\begin{array}{l}\text { The subsidy ratio provided by the } \\
\text { governments }\end{array}$ \\
\hline$\pi_{e}$ & The estimated revenue of the investors \\
\hline$\pi_{r} / \pi_{r}(a)$ & The actual revenue of the investors \\
\hline$a$ & The efforts expended by the investors \\
\hline$C / C(a)$ & $\begin{array}{l}\text { The operation cost paid during the } \\
\text { operation stage }\end{array}$ \\
\hline$b(b>0)$ & $\begin{array}{l}\text { The cost coefficient for effort expended } \\
\text { by the investors }\end{array}$ \\
\hline$\theta\left(\theta \sim N\left(0, \sigma^{2}\right)\right)$ & $\begin{array}{l}\text { A random variable of a normal } \\
\text { distribution }\end{array}$ \\
\hline$U_{1}$ & $\begin{array}{l}\text { The expected utility of the governments } \\
\text { without altruism }\end{array}$ \\
\hline$U_{2}$ & $\begin{array}{l}\text { The expected utility of the investors } \\
\text { without altruism }\end{array}$ \\
\hline$\varepsilon_{1}\left(\varepsilon_{1} \in[0,1]\right)$ & The altruism of the governments \\
\hline$\varepsilon_{2}\left(\varepsilon_{2} \in[0,1]\right)$ & The altruism of the investors \\
\hline$U_{1}^{*}$ & $\begin{array}{l}\text { The expected utility of the governments } \\
\text { with altruistic preferences }\end{array}$ \\
\hline$U_{2}^{*}$ & $\begin{array}{l}\text { The expected utility of the investors with } \\
\text { altruistic preferences }\end{array}$ \\
\hline
\end{tabular}
utility needs to be maximized first. To ensure sufficient attractiveness of the projects, the utilities of the private investors should also be maximized. On the other hand, the investors by default are exposed to different opportunities

Table 1. The definitions of the variables

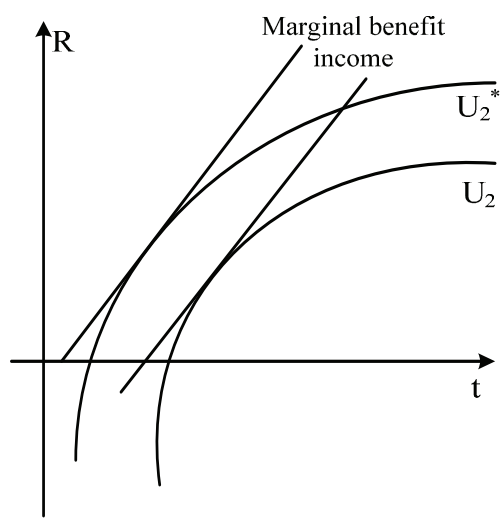

Figure 3. Two kinds of investors' utilities 
to invest in various other projects, there will be an average return that they can get based on their experiences. Assume the average return be denoted as $U_{0}$. Then, the principal-agent model can be designed as follows:

$$
\begin{aligned}
& \max _{p}\left\{(1-p)\left(\pi_{e}-a\right)+\varepsilon_{1}\left[a+p\left(\pi_{e}-a\right)-\frac{1}{2} b a^{2}\right]\right\} ; \\
& a+p\left(\pi_{e}-a\right)-\frac{1}{2} b a^{2}+\varepsilon_{2}(1-p)\left(\pi_{e}-a\right) \geq U_{0} ; \quad \text { s.t. (IR) } \\
& \max \left\{a+p\left(\pi_{e}-a\right)-\frac{1}{2} b a^{2}+\varepsilon_{2}(1-p)\left(\pi_{e}-a\right)\right\} ; \text { s.t. (IC) } \\
& a^{*}=\frac{\left(1-\varepsilon_{2}\right)(1-p)}{b} .
\end{aligned}
$$

where: (IR) is the set of constraints that ensures investor's participation in the project; (IC) represents investors' profit-driven nature; (IC') is the first-order equivalent condition of (IC).

In practice, considering the uniqueness of a project that all procedures of decision-making and construction cannot be repeated, this is a non-repetitive game process between the governments and investors. During this oneoff game process, their altruism is a kind of inherent quality and will not be influenced by others' strategies. Then, substituting (IC') into the objective function, the firstorder optimality condition is:

$$
\begin{aligned}
& p^{*}=\frac{b \pi_{e}\left(\varepsilon_{1}-1\right)}{\left(1-\varepsilon_{2}\right)\left(2-\varepsilon_{1}-\varepsilon_{1} \varepsilon_{2}\right)}+1 ; \\
& a^{*}=\frac{\pi_{e}\left(1-\varepsilon_{1}\right)}{2-\varepsilon_{1}-\varepsilon_{1} \varepsilon_{2}},
\end{aligned}
$$

where: $p^{*}$ is the governments' optimal compensation ratio and $a^{*}$ is the highest level of efforts that the investors will choose to put forth.

\section{Model analysis and discussion}

The PPP arrangements essentially emphasize risk sharing mechanism by both governments and private investors. In order to analyse how altruistic preferences affect performances of both sides, the relationships between the optimal compensation ratio provided by governments $p^{*}$ and the investors' chosen level of efforts $a^{*}$, the utilities of both parties $\left(U_{1}^{*}\right.$ and $\left.U_{2}^{*}\right)$ and their altruism $\left(\varepsilon_{1}\right.$ and $\left.\varepsilon_{2}\right)$ need to be discussed.

Proposition 1. Only investors with a professional operation ability and a rational expected revenue level could earn opportunities of participating in PPP projects sponsored by governments.

Confirmation: As $p^{*}$ should be a positive value, it can be deduced that $b \pi_{e}<\frac{\left(1-\varepsilon_{2}\right)\left(2-\varepsilon_{1}-\varepsilon_{1} \varepsilon_{2}\right)}{1-\varepsilon_{1}}$. This inequality demonstrates that when the cost coefficient of investors' efforts $(b)$ is a constant and their expected rev- enue $\left(\pi_{e}\right)$ is too high (i.e., $\left.\pi_{e}>\frac{\left(1-\varepsilon_{2}\right)\left(2-\varepsilon_{1}-\varepsilon_{1} \varepsilon_{2}\right)}{b\left(1-\varepsilon_{1}\right)}\right)$, the optimal government compensation ratio $\left(p^{*}\right)$ will be less than zero. As a result, in this case $p^{*}=0$, which means that the governments will not take any risk. In other words, the governments will not choose the investors as

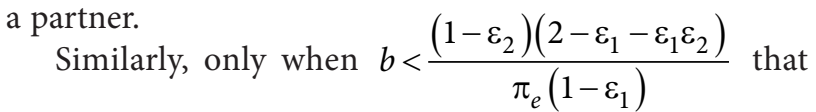
the investors will participate in PPP projects. Comparing two investors whose profitability are at the same level, a higher value of $\pi_{e}$ means a larger difference between the real and estimated revenue, and conversely the governments will need to provide less guarantees, namely $p^{*}$ declines. Likewise, when the expected revenues of the investors are same, a higher $b$ represents worse operational capability of the investors, which will also result in the governments shouldering less expenditure risks instead (i.e. $p^{*}$ decreases). In practice, investors should not expect excessive returns $\left(\pi_{e}\right)$, in case of losing the chance to participate in PPP projects. As for governments, they should utilize appropriate means to reduce the effort cost of investors $(b)$, such as in-time sharing of information and technology.

Proposition 2. Investors are more likely to secure a winning chance of investment when the altruism of governments is high. However, investors' high altruism cannot bring themselves governments' favour.

Confirmation: As mentioned above, investors with the quality of $b \pi_{e}<\frac{\left(1-\varepsilon_{2}\right)\left(2-\varepsilon_{1}-\varepsilon_{1} \varepsilon_{2}\right)}{1-\varepsilon_{1}}$ could be chosen by the governments. Considering two factors $\varepsilon_{1}$ and $\varepsilon_{2}$ affecting the above situation: $\frac{\left(1-\varepsilon_{2}\right)\left(2-\varepsilon_{1}-\varepsilon_{1} \varepsilon_{2}\right)}{1-\varepsilon_{1}}$ is positively correlated to $\varepsilon_{1}$ and negatively correlated with $\varepsilon_{2}$. With an increased value of $\varepsilon_{1}$, the investors are more likely to be chosen. On the contrary, a higher value of $\varepsilon_{2}$ makes $b \pi_{e}$ even harder to be lower than $\frac{\left(1-\varepsilon_{2}\right)\left(2-\varepsilon_{1}-\varepsilon_{1} \varepsilon_{2}\right)}{1-\varepsilon_{1}}$, which means that the investors are not preferred in this scenario.

In PPP projects, high altruism of the governments can drive them considering less of investors' conditions. They pursue to serve the public and construct the required infrastructure as soon as possible. Therefore, the investors have higher chances of succeeding in this situation. On the other hand, excessive altruism exhibited by the investors may be questioned by the governments. Typically, the governments always consider the rationality of investors' performance based on their profit-driven nature. Too many benefits provided during the first stage may bring more potential risks, such as making profits by cutting corners. As a result, for investors, subscribing to a proper level of altruism is important when cooperating with the governments. 
Proposition 3. In PPP projects, the effort level of investors is positively correlated to their altruism and negatively correlated to the governments' altruism.

Confirmation: In reality, the effort levels of investors are hard to be observed. However, it could be affected by the altruistic preferences of both the investors and the governments. Specifically, the investors' level of efforts is positively correlated to their altruism and negatively correlated to the governments' altruism. As mentioned, an ethical mind could generate a positive impact on the participants' behaviour. The investors' altruistic preferences, which means a higher value of $\varepsilon_{2}$, will lead them to pay more attention to the public interests. Therefore, in the process of maximizing profits, the investors' altruism will also help to improve project efficiency. Conversely, excessive government altruism may create investors' psychological dependence and will not induce investors to expend more efforts. In this scenario, private investors do not have the pressure on profits since they are subsidized by the governments. This confirms the complex nature of project management: a higher level of efforts given by project managers does not always translate to a better project, whereas lower altruism may actually increase the investors' productivity (Dur \& Tichem, 2015). The investors' estimated revenue $\pi_{e}$ also has a positive effect on the investors' efforts. Apparently, the more revenue the investors want to obtain, the more efforts they need to expend. This forms the basis for our mathematical expressions $\left(\frac{\partial a^{*}}{\partial \varepsilon_{1}}=\frac{\varepsilon_{2}-1}{\left(2-\varepsilon_{1}-\varepsilon_{1} \varepsilon_{2}\right)^{2}}<0\right.$ and $\left.\frac{\partial a^{*}}{\partial \varepsilon_{2}}=\frac{\varepsilon_{1}\left(1-\varepsilon_{1}\right)}{\left(2-\varepsilon_{1}-\varepsilon_{1} \varepsilon_{2}\right)^{2}}>0\right)$ for PPP projects. The relationships between $a^{*}$ and $\varepsilon_{1}, \varepsilon_{2}$ is shown in Figure 4 , simulated by the software MATLAB, which is a preferred commercial mathematic tool and widely applied for advanced technical computing language and interactive environment of algorithm development, data visualization, data analysis and numerical calculation nowadays. According to the above analysis, in order to expect investors to invest the optimal level of productive efforts $\left(a^{*}\right)$, governments should appropriately reduce their altruistic preferences instead, while should set some preferential terms to enhancing investors' altruism.

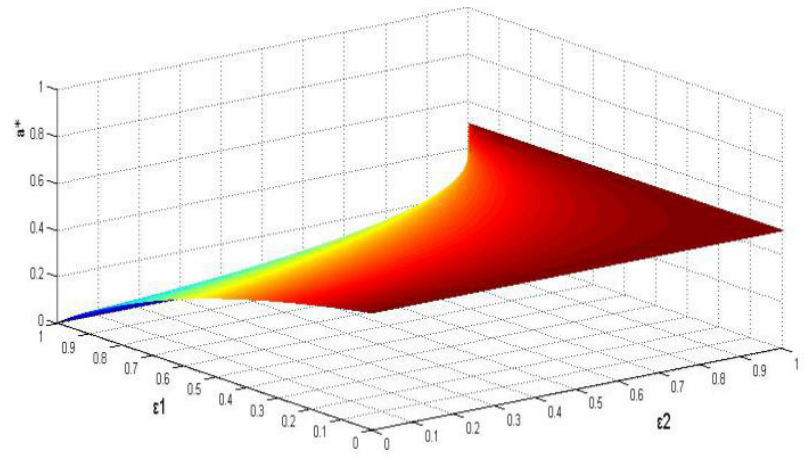

Figure 4. Relationships between $a^{*}$ and $\varepsilon_{1}, \varepsilon_{2}$
Proposition 4. The government compensation ratio positively correlates to their altruism and negatively correlates with the investors' altruism.

Confirmation: Legitimately, a high value of $\varepsilon_{1}$ reflects that the governments intend to attract more investments to facilitate infrastructure development in PPP projects. Conversely, if the investors prefer to share more risks arising from their high level of altruism $\varepsilon_{2}$, then the risktaking burden of governments could be reduced. Quantificationally, $\frac{\partial p^{*}}{\partial \varepsilon_{1}}=\frac{1-\varepsilon_{2}}{\left[\left(1-\varepsilon_{2}\right)\left(2-\varepsilon_{1}-\varepsilon_{1} \varepsilon_{2}\right)\right]^{2}}>0$ and $\frac{\partial p^{*}}{\partial \varepsilon_{2}}=\frac{2 b \pi_{e}\left(1-\varepsilon_{1}\right)\left(\varepsilon_{1} \varepsilon_{2}-1\right)}{\left[\left(1-\varepsilon_{2}\right)\left(2-\varepsilon_{1}-\varepsilon_{1} \varepsilon_{2}\right)\right]^{2}}<0$. The relationships between $p^{*}$ and $\varepsilon_{1}, \varepsilon_{2}$ is demonstrated in Figure 5. In this scenario, different from the implications from proposition 3, only the governments present a higher level of altruism but private investors have a relatively low level will the investors can obtain more government subsidies.

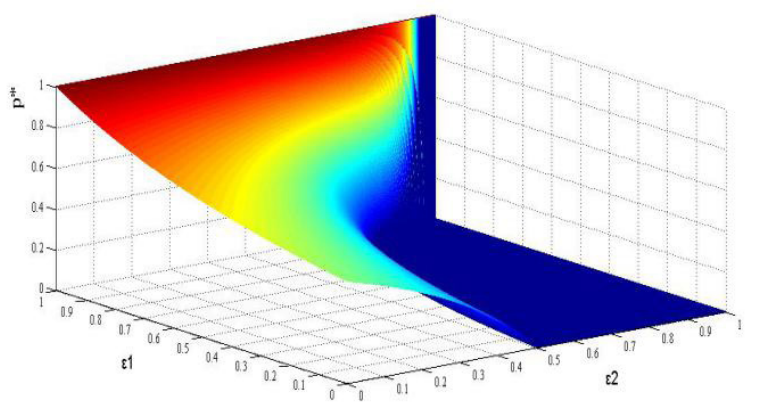

Figure 5. Relationships between $p^{*}$ and $\varepsilon_{1}, \varepsilon_{2}$

Proposition 5. If the governments are fully selfish, i.e. $\varepsilon_{1}=0$ and $\varepsilon_{2}>0$, then it will be deduced that $a_{\varepsilon_{1}=0}^{*}=\frac{\pi_{e}}{2}, p_{\varepsilon_{1}=0}^{*}=1-\frac{b \pi_{e}}{2\left(1-\varepsilon_{2}\right)}$. Whereas, the investors possess no altruism, where $\varepsilon_{1}>0$ and $\varepsilon_{2}=0$, and their level of efforts becomes $a_{\varepsilon_{2}=0}^{*}=\frac{1-\varepsilon_{1}}{2-\varepsilon_{1}} \pi_{e}$.

Confirmation: When the governments present no altruistic preferences, i.e. $\varepsilon_{1}=0$, investors' altruism (i.e. $\varepsilon_{2}>0$ ) can only affect the government compensation ratio, and their effort level is a constant which is related to the expected revenue. Without the government incentive, there will not be enough motivation for the investors to expend a high level of efforts. Obviously, $a_{\varepsilon_{1}=0}^{*}>a_{\varepsilon_{2}=0}^{*}$ demonstrates that governments' altruism may breed investors' speculation, which should be highly noted when designing incentives.

Proposition 6. Both the expected utilities $\left(U_{1}^{*}\right.$ and $U_{2}^{*}$ ) of the governments and the investors are positively correlated with their altruistic preferences $\left(\varepsilon_{1}\right.$ and $\left.\varepsilon_{2}\right)$, respectively. 


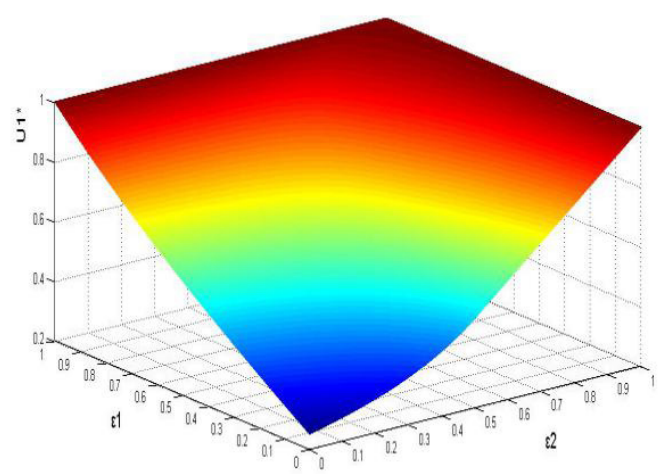

Figure 6. Relationships between $U_{1}^{*}$ and $\varepsilon_{1}, \varepsilon_{2}$

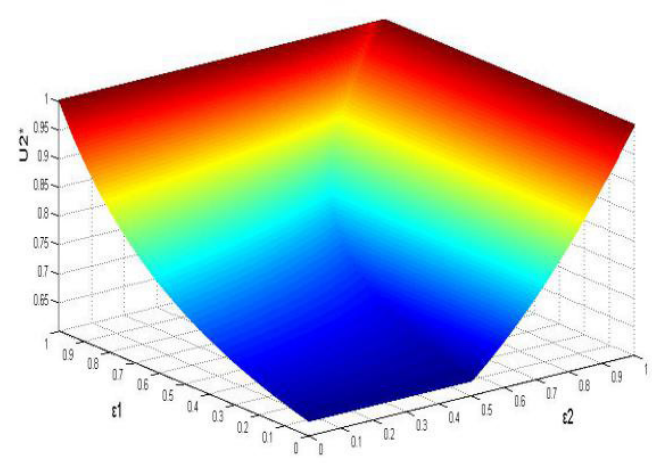

Figure 7. Relationships between $U_{2}^{*}$ and $\varepsilon_{1}, \varepsilon_{2}$

Confirmation: Not only that an "altruistic mind" will promote sustainable development of investors, but also help to increase public benefits. The relationships between $U_{1}^{*}$ and $\varepsilon_{1}, \varepsilon_{2} ; U_{2}^{*}$ and $\varepsilon_{1}, \varepsilon_{2}$ are shown in Figure 6 and Figure 7. Compared with Figure 6, the investors' utilities are more sensitive to the governments' altruism. According to Figure 7 , when $\varepsilon_{1}$ is very small (say, equal to 0.1 ) and even when $\varepsilon_{2}$ increases to 0.55 , the value of $U_{2}^{*}$ is not growing synchronously. As the project sponsor and policy-maker, the governments can affect investors' revenue by setting incentives. Proper inventive mechanisms (such as appropriate tax exemption and recognition of the enterprise) will not increase the financial burden of the governments, but can effectively improve the utility value of the investors.

\section{Numerical example}

Nowadays, the number of altruistic PPP projects, such as in the field of ecological construction and environmental protection, health and senior care and education etc., has been increasing year by year (An et al., 2018; Xu et al., 2015). Due to the large demand for such projects but the low rate of return, an effective policy or mechanism is essential to attract private investors to participate (Solana, 2014). However, the government guarantees for investors' minimum profits are illegal. Giving full play to investors' altruistic preferences reasonably through risking shar- ing, helping to achieve their social responsibilities, has an important impact on the efficiency improvement of PPP cooperation.

In order to describe the proposed model in this paper more intuitively, a numerical simulation is presented. Generally, the private investors understand their own effort costs $(b)$ and the expected revenue $\left(\pi_{e}\right)$ of participating in the projects clearly. In the ideal case, the governments can comprehend these two parameters through the investors' past performance of the previous PPP projects that they have participated in. Also, data can be collected via using some objective measures, to determine whether to cooperate with these investors or not. Once the governments select appropriate investors as a partner, some techniques can be used to measure the altruistic preferences of both the governments and the investors. For instance, taking laboratory experiment into account, some subjects with certain experiences could be selected first, then provided with the necessary background information to simulate the investors' behaviour. Questionnaires could also be designed to collect data if necessary. Actually, the altruistic preferences of the governments and the private investors are different. Based on whether the governments and investors have altruistic preferences, there are three scenarios, including only one of the governments or private investors having altruism (e.g. scenarios 1 and 2), neither both sides having this preference (e.g. scenario 3 ) and both parties having altruistic preferences (e.g. scenario 4). Given many possibilities for the parameters of the investors and governments, values of the mentioned parameters based on various situations are assigned.

First, assume only investors have altruistic preferences and the government totally has no concern about the investors' benefits. As shown in Table 2, the investors take all the revenue risk. When $\pi_{e}$ is a constant, the cost coefficient for effort expended by investors ( $b$ ) only has impact on investors' utility. In the opposite scenario, when $b$ is a constant, an increased expected revenue $\pi_{e}$ (from 0.5 to 0.9 ) will drive investors to expend more efforts (from 0.25 to 0.45 ), which as a result improves the utilities of both parties. This implies that inherent revenue momentum has a huge incentive effect. In this scenario, the investors still prefer to participate in a project even though the governments do not provide any guarantee, indicating that either the project is extremely profitable or that the investors urgently need to boost up their reputation by cooperating with the government.

Next, assume that the investors totally have no concern about others' benefits and the governments take all the revenue risk. According to simulated results, the utilities of both parties will not change no matter how $b$ varies. Similar to some disaster relief projects, the decisionmaking of PPP project is urgent, the governments have no better approach than to implement the project as soon as possible by offering attractive incentives. As a result, the investors will not pay much attention to their cost coefficients. Although the governments will earn a good reputation and investors could secure a good amount of 
Table 2. Numerical simulation

\begin{tabular}{|c|c|c|c|c|c|c|c|c|}
\hline Scenarios & $b$ & $\pi_{e}$ & $\varepsilon_{1}$ & $\varepsilon_{2}$ & $p^{*}$ & $a^{*}$ & $U_{1}^{*}$ & $U_{2}^{*}$ \\
\hline \multirow[t]{6}{*}{1} & 0.50 & \multirow[t]{3}{*}{0.50} & \multirow[t]{6}{*}{0.00} & \multirow[t]{6}{*}{0.99} & 0.00 & 0.25 & 0.25 & 0.48 \\
\hline & 0.70 & & & & 0.00 & 0.25 & 0.25 & 0.48 \\
\hline & 0.90 & & & & 0.00 & 0.25 & 0.25 & 0.47 \\
\hline & \multirow[t]{3}{*}{0.50} & 0.50 & & & 0.00 & 0.25 & 0.25 & 0.48 \\
\hline & & 0.70 & & & 0.00 & 0.35 & 0.35 & 0.67 \\
\hline & & 0.90 & & & 0.00 & 0.45 & 0.45 & 0.84 \\
\hline \multirow[t]{3}{*}{2} & 0.50 & \multirow[t]{3}{*}{0.50} & \multirow[t]{3}{*}{1.00} & \multirow[t]{3}{*}{0.00} & 1.00 & 0.00 & 0.50 & 0.50 \\
\hline & 0.70 & & & & 1.00 & 0.00 & 0.50 & 0.50 \\
\hline & 0.90 & & & & 1.00 & 0.00 & 0.50 & 0.50 \\
\hline \multirow[t]{3}{*}{3} & 0.50 & \multirow[t]{3}{*}{0.50} & \multirow[t]{3}{*}{0.00} & \multirow[t]{3}{*}{0.00} & 0.88 & 0.25 & 0.03 & 0.45 \\
\hline & 0.70 & & & & 0.83 & 0.25 & 0.04 & 0.43 \\
\hline & 0.90 & & & & 0.78 & 0.25 & 0.06 & 0.42 \\
\hline \multirow[t]{5}{*}{4} & \multirow[t]{5}{*}{0.50} & \multirow[t]{5}{*}{0.50} & \multirow[t]{5}{*}{0.05} & 0.10 & 0.86 & 0.24 & 0.06 & 0.45 \\
\hline & & & & 0.30 & 0.82 & 0.25 & 0.07 & 0.45 \\
\hline & & & & 0.50 & 0.75 & 0.25 & 0.08 & 0.45 \\
\hline & & & & 0.70 & 0.59 & 0.25 & 0.12 & 0.45 \\
\hline & & & & 0.90 & 0.00 & 0.25 & 0.26 & 0.46 \\
\hline
\end{tabular}

benefits, the level of investors' effort cannot be improved, which indicates that the governments' high altruism does in fact undermine the incentive effect.

Then, assume that the altruistic preferences of both two parties are equal to zero. This the special scenario of this paper. Compared to scenario 1, the utilities of both parties are lower, and the decline in governments' utility is particularly severe. This is because the governments have to shoulder more risks while the investors only care about their own profitability. This emphasizes the importance of considering altruistic preferences in increasing utilities again.

Fourth, when the degree of the governments' altruism is extremely small, say $\varepsilon_{1}=0.05$, increasing investors' altruism can hardly affect their level of efforts expended and utility generated, which may damage the investors' interest in participating in the project. Conclusions shown in Figure 7 of part 4 could be verified.

\section{Conclusions}

Different from the original motivation of the "economic man" to maximize self-interests, the results of this study illustrate that non-subjective altruism will help private investors and the governments to achieve a better win-win contract. The governments can take advantage of altruism to guide investors into expending a high level of efforts and maximize the utility levels of both parties. Examples of such altruism include offering proper guarantees to share risks and enhancing the cooperative goal through the media publicity.

In PPP projects, the relationships between the governments and the investors can be interpreted via the principal-agent model. As the sponsor and incentive decision-maker of the projects, the governments should set an optimal subsidy mechanism to attract investments as well as making the best use of both parties' altruism. In PPP projects, both parties' utilities are determined by the subsidy ratio provided by governments $\left(p^{*}\right)$ and the efforts expended by the investors $\left(a^{*}\right)$ directly, and are also positively correlated with their altruistic preferences $\left(\varepsilon_{1}\right.$ and $\left.\varepsilon_{2}\right)$ respectively. Specifically, the government compensation ratio $\left(p^{*}\right)$ positively correlates to their altruism $\left(\varepsilon_{1}\right)$ and negatively correlates with the investors' altruism $\left(\varepsilon_{2}\right)$, while the effort level of investors $\left(a^{*}\right)$ improves with their increased altruism $\left(\varepsilon_{2}\right)$ and decreases with the increased altruism of governments $\left(\varepsilon_{1}\right)$. In spite of this, an excessive altruism of governments $\left(\varepsilon_{1}\right)$ is harmful to the expended effort level of investors $\left(a^{*}\right)$. Correspondingly, a high level of investors' altruistic preferences $\left(\varepsilon_{2}\right)$ may cause suspicion of the governments $\left(p^{*}\right)$, which will result in a failed bid. The comparison of two scenarios when governments are fully selfish (i.e., $\varepsilon_{1}=0$ and $\varepsilon_{2}>0$ ) or the investors possess no altruism (i.e., $\varepsilon_{1}>0$ and $\varepsilon_{2}=0$ ) demonstrates that $a_{\varepsilon_{1}=0}^{*}>a_{\varepsilon_{2}=0}^{*}$ and that governments' altruism may breed investors' speculation. Additionally, both the investors' expected revenue $\left(\pi_{e}\right)$ and the effort cost $(b)$ have a negative impact on the government subsidies $\left(p^{*}\right)$; but the investors' expected revenue $\left(\pi_{e}\right)$ affect the efforts invested by investors $\left(a^{*}\right)$ positively, with the prerequisite for the effort cost $b<\frac{\left(1-\varepsilon_{2}\right)\left(2-\varepsilon_{1}-\varepsilon_{1} \varepsilon_{2}\right)}{\pi_{e}\left(1-\varepsilon_{1}\right)}$. The results provide a quantitative reference for the decision-making of both governments and private investors with altruism in PPP projects. 
In practice of PPP schemes, the role of governments for an appropriate government subsidy incentive is crucial. (1) First, the governments should investigate the operating background of private investors carefully to identify their expected revenue $\left(\pi_{e}\right)$. (2) Meanwhile, governments ought to express altruism $\left(\varepsilon_{1}\right)$ from various perspectives, such as providing clear reward system, enhancing the relatively fair and enabling market environment, less corrupt governance and presenting a great opportunity of financing for private investors to engaging in PPP projects. But it is not that the stronger the intensity of altruism $\left(\varepsilon_{1}\right)$, the better; the degree of altruism $\left(\varepsilon_{1}\right)$ is neither too severe nor too light, and the governments need to balance the relationship between the investors' efforts $\left(a^{*}\right)$ and the government subsidies $\left(p^{*}\right)$ based on the specific scenario of different PPP projects. For private investors, (1) they can make some attempts (such as questionnaire and scenario simulation) to analyse the altruism of governments. Only they with a professional operation ability $(b)$ and a rational expected revenue level $\left(\pi_{e}\right)$ could earn opportunities of participating in PPP projects sponsored by governments. For instance, investors can apply some advanced techniques and share the information in time to reduce the cost of efforts (b); (2) furthermore, investors should increase the awareness of altruism $\left(\varepsilon_{2}\right)$ properly. This requires that private investors should also be fully aware of the great importance of altruism during cooperation, which can be treated as a process of maximizing benefits in PPP projects.

In conclusion, the contribution of the paper is to formulate an incentive mechanism in PPP projects for efficient governance based on altruism using principalagent theory. The findings contribute new insights into the development between the government subsidies and the altruistic preferences, severing as a reference when both the governments and investors make decisions in PPP projects. However, as the study of altruism is still evolving, there is no complete system to measure the preference parameters of project participants. Therefore, it is difficult to test the theoretical conclusions by using real cases. And also the game is a dynamic program, which means that the performances and strategies of both the governments and investors are changing during the cooperation process. Thus, the study of interactions between the governments and the investors with their altruistic preferences should continue to be groomed as a future direction of researches.

\section{Acknowledgements}

The authors thank the Fujian Agriculture and Forestry University Outstanding Youth Research Talents Program (grant number xjq201823) and the National Natural Science Foundation of China (grant numbers 71901068, 71571149). We also thank the anonymous reviewers for their comments.

\section{Author contributions}

Yinglin Wang and Ruolan Gao conceived the study and were responsible for the research design and methodology. Yinglin Wang, Ruolan Gao and Jicai Liu were responsible for the model development and numerical example. Jicai Liu and Bon-Gang Hwang developed the data analysis and the conclusion.

\section{Disclosure statement}

The authors declare that they have no competing financial, professional, or personal interests from other parties.

\section{References}

Almassi, A., McCabe, B., \& Thompson, M. (2012). Real optionsbased approach for valuation of government guarantees in public-private partnerships. Journal of Infrastructure Systems, 19(2), 196-204.

https://doi.org/10.1061/(ASCE)IS.1943-555X.0000117

Alonso-Conde, A. B., Brown, C., \& Rojo-Suarez, J. (2007). Public private partnerships: incentives, risk transfer and real options. Review of Financial Economics, 16(4), 335-349.

https://doi.org/10.1016/j.rfe.2007.03.002

An, X., Li, H., Wang, L., Wang, Z., Ding, J., \& Cao, Y. (2018). Compensation mechanism for urban water environment treatment PPP project in China. Journal of Cleaner Production, 201, 246-253. https://doi.org/10.1016/j.jclepro.2018.08.003

Andreoni, J., \& Miller, J. (2002). Giving according to GARP: an experimental test of the consistency of preferences for altruism. Econometrica, 70(2), 737-753. https://doi.org/10.1111/1468-0262.00302

Borghesi, R., Houston, J. F., \& Naranjo, A. (2014). Corporate socially responsible investments: CEO altruism, reputation, and shareholder interests. Journal of Corporate Finance, 26, 164-181. https://doi.org/10.1016/j.jcorpfin.2014.03.008

Brown, M., Falk, A., \& Fehr, E. (2004). Relational contracts and the nature of market interactions. Econometrica, 72(3), 747780. https://doi.org/10.1111/j.1468-0262.2004.00511.x

Brown, M., Falk, A., \& Fehr, E. (2012). Competition and relational contracts: the role of unemployment as a disciplinary device. Journal of the European Economic Association, 10(4), 887-907. https://doi.org/10.1111/j.1542-4774.2011.01058.x

Buyukyoran, F., \& Gundes, S. (2018). Optimized real optionsbased approach for government guarantees in PPP toll road projects. Construction Management and Economics, 36(4), 203-216. https://doi.org/10.1080/01446193.2017.1347267

Carbonara, N., \& Pellegrino, R. (2018). Revenue guarantee in public-private partnerships: a win-win model. Construction Management and Economics, 36(10), 584-598. https://doi.org/10.1080/01446193.2018.1467028

Carbonara, N., Costantino, N., \& Pellegrino, R. (2014a). Concession period for PPPs: a win-win model for a fair risk sharing. International Journal of Project Management, 32(7), 12231232. https://doi.org/10.1016/j.ijproman.2014.01.007

Carbonara, N., Costantino, N., \& Pellegrino, R. (2014b). Revenue guarantee in public-private partnerships: a fair risk allocation model. Construction Management and Economics, 32(4), 403415. https://doi.org/10.1080/01446193.2014.906638 
Carroll, A. B. (1991). The pyramid of corporate social responsibility: toward the moral management of organizational stakeholders. Business Horizons, 34(4), 39-48. https://doi.org/10.1016/0007-6813(91)90005-G

Carvalho, C., \& Nechio, F. (2011). Aggregation and the PPP puzzle in a sticky-price model. American Economic Review, 101(6), 2391-2424. https://doi.org/10.1257/aer.101.6.2391

Cheah, C. Y., \& Liu, J. (2006). Valuing governmental support in infrastructure projects as real options using Monte Carlo simulation. Construction Management and Economics, 24(5), 545-554. https://doi.org/10.1080/01446190500435572

De Waal, F. B. (2008). Putting the altruism back into altruism: the evolution of empathy. Annual Review of Psychology, 59, 279300. https://doi.org/10.1146/annurev.psych.59.103006.093625

Dur, R., \& Tichem, J. (2015). Altruism and relational incentives in the workplace. Journal of Economics \& Management Strategy, 24(3), 485-500. https://doi.org/10.1111/jems.12099

Elster, J. (2006). Altruistic behavior and altruistic motivations. In Handbook of the economics of giving, altruism and reciprocity: Foundations (Vol. 1, pp. 183-206). Netherlands: North-Holland. https://doi.org/10.1016/S1574-0714(06)01003-7

Fahad Al-Azemi, K., Bhamra, R., \& Salman, A. F. (2014). Risk management framework for build, operate and transfer (BOT) projects in Kuwait. Journal of Civil Engineering and Management, 20(3), 415-433.

https://doi.org/10.3846/13923730.2013.802706

Feng, Z., Zhang, S. B., \& Gao, Y. (2015). Modeling the impact of government guarantees on toll charge, road quality and capacity for Build-Operate-Transfer (BOT) road projects. Transportation Research Part A: Policy and Practice, 78, 5467. https://doi.org/10.1016/j.tra.2015.05.006

Fehr, E., \& Fischbacher, U. (2003). The nature of human altruism. Nature, 425(6960), 785-791. https://doi.org/10.1038/nature02043

Galera, A. L. L., \& Soliño, A. S. (2010). A real options approach for the valuation of highway concessions. Transportation Science, 44(3), 416-427. https://doi.org/10.1287/trsc.1090.0299

$\mathrm{Ge}, \mathrm{Z}$., \& Hu, Q. (2012). Who benefits from altruism in supply chain management? American Journal of Operations Research, 2(01), 59-72. https://doi.org/10.4236/ajor.2012.21007

Ge, Z., Zhang, Z. K., Lü, L., Zhou, T., \& Xi, N. (2012). How altruism works: an evolutionary model of supply networks. Physica A: Statistical Mechanics and its Applications, 391(3), 647-655. https://doi.org/10.1016/j.physa.2011.08.063

Gino, F., \& Pisano, G. (2008). Toward a theory of behavioral operations. Manufacturing \& Service Operations Management, 10(4), 676-691. https://doi.org/10.1287/msom.1070.0205

Holmstrom, B., \& Milgrom, P. (1987). Aggregation and linearity in the provision of intertemporal incentives. Econometrica: Journal of the Econometric Society, 55(2), 303-328. https://doi.org/10.2307/1913238

Hosoda, T., \& Disney, S. M. (2006). The governing dynamics of supply chains: the impact of altruistic behaviour. Automatica, 42(8), 1301-1309. https://doi.org/10.1016/j.automatica.2006.03.013

Jin, X. H., \& Zhang, G. (2011). Modelling optimal risk allocation in PPP projects using artificial neural networks. International Journal of Project Management, 29(5), 591-603. https://doi.org/10.1016/j.ijproman.2010.07.011

Ke, Y., Wang, S., \& Chan, A. P. (2010a). Risk allocation in public-private partnership infrastructure projects: comparative study. Journal of Infrastructure Systems, 16(4), 343-351. https://doi.org/10.1061/(ASCE)IS.1943-555X.0000030

Ke, Y., Wang, S., Chan, A. P., \& Lam, P. T. (2010b). Preferred risk allocation in China's public-private partnership (PPP) projects. International Journal of Project Management, 28(5), 482-492. https://doi.org/10.1016/j.ijproman.2009.08.007
Kułakowski, K., \& Gawroński, P. (2009). To cooperate or to defect? Altruism and reputation. Physica A: Statistical Mechanics and its Applications, 388(17), 3581-3584.

https://doi.org/10.1016/j.physa.2009.05.001

Liu, J., Gao, R., \& Cheah, C. Y. J. (2017). Pricing mechanism of early termination of PPP projects based on real option theory. Journal of Management in Engineering, 33(6), 04017035. https://doi.org/10.1061/(ASCE)ME.1943-5479.0000556

Liu, J., Yu, X., \& Cheah, C. Y. J. (2014). Evaluation of restrictive competition in PPP projects using real option approach. International Journal of Project Management, 32(3), 473-481. https://doi.org/10.1016/j.ijproman.2013.07.007

Loch, C. H., \& Wu, Y. (2008). Social preferences and supply chain performance: an experimental study. Management Science, 54(11), 1835-1849. https://doi.org/10.1287/mnsc.1080.0910

Marzouk, M., \& Ali, M. (2018). Mitigating risks in wastewater treatment plant PPPs using minimum revenue guarantee and real options. Utilities Policy, 53, 121-133. https://doi.org/10.1016/j.jup.2018.06.012

Moore, M. A., Boardman, A. E., \& Vining, A. R. (2017). Analyzing risk in PPP provision of utility services: a social welfare perspective. Utilities Policy, 48, 210-218. https://doi.org/10.1016/j.jup.2017.08.008

Nandavar, S., Lewis, I., \& White, K. M. (2019). Understanding drivers' altruistic driving decisions: a theoretically guided investigation. Transportation Research Part F: Traffic Psychology and Behaviour, 62, 212-227.

https://doi.org/10.1016/j.trf.2018.12.017

Nasirzadeh, F., Khanzadi, M., \& Rezaie, M. (2014). Dynamic modeling of the quantitative risk allocation in construction projects. International Journal of Project Management, 32(3), 442-451. https://doi.org/10.1016/j.ijproman.2013.06.002

Pellegrino, R., Ranieri, L., Costantino, N., \& Mummolo, G. (2011). A real options-based model to supporting risk allocation in price cap regulation approach for public utilities. Construction Management and Economics, 29(12), 1197-1207. https://doi.org/10.1080/01446193.2011.647828

Piliavin, J. A. (2009). Altruism and helping: the evolution of a field: the 2008 Cooley-Mead presentation. Social Psychology Quarterly, 72(3), 209-225.

https://doi.org/10.1177/019027250907200305

Shi, K., Jiang, F., \& Ouyang, Q. (2013). Altruism and pricing strategy in dual-channel supply chains. American Journal of Operations Research, 3(4), 402-412.

https://doi.org/10.4236/ajor.2013.34038

Shi, S., Yin, Y., \& Guo, X. (2016). Optimal choice of capacity, toll and government guarantee for build-operate-transfer roads under asymmetric cost information. Transportation Research Part B: Methodological, 85, 56-69.

https://doi.org/10.1016/j.trb.2015.12.019

Salas, P. C., \& Roe, B. E. (2012). The role of cooperation and reciprocity in structuring carbon sequestration contracts in developing countries. American Journal of Agricultural Economics, 94(2), 411-418. https://doi.org/10.1093/ajae/aar108

Solana, E. F. O. (2014). Public private not-for-profit partnerships: delivering public services to developing countries. Procedia Engineering, 78, 259-264.

https://doi.org/10.1016/j.proeng.2014.07.065

Song, J., Zhao, Y., Jin, L., \& Sun, Y. (2018). Pareto optimization of public-private partnership toll road contracts with government guarantees. Transportation Research Part A: Policy and Practice, 117, 158-175.

https://doi.org/10.1016/j.tra.2018.08.019 
Soumaré, I. (2016). An analysis of government loan guarantees and direct investment through public-private partnerships. Economic Modelling, 59, 508-519.

https://doi.org/10.1016/j.econmod.2016.08.012

Sun, Y., \& Zhang, L. (2014). Balancing public and private stakeholder interests in BOT concessions: minimum revenue guarantee and royalty scheme applied to a water treatment project in China. Journal of Construction Engineering and Management, 141(2), 04014070.

https://doi.org/10.1061/(ASCE)CO.1943-7862.0000930

Urda, J., \& Loch, C. H. (2013). Social preferences and emotions as regulators of behavior in processes. Journal of Operations Management, 31(1-2), 6-23. https://doi.org/10.1016/j.jom.2012.11.007

Wang, Y., Cui, P., \& Liu, J. (2018). Analysis of the risk-sharing ratio in PPP projects based on government minimum revenue guarantees. International Journal of Project Management, 36(6), 899-909. https://doi.org/10.1016/j.ijproman.2018.01.007

Wang, Y., Gao, H. O., \& Liu, J. (2019). Incentive game of investor speculation in PPP highway projects based on the government minimum revenue guarantee. Transportation Research Part A: Policy and Practice, 125, 20-34. https://doi.org/10.1016/j.tra.2019.05.006

Wang, Y., \& Liu, J. (2015). Evaluation of the excess revenue sharing ratio in PPP projects using principal-agent models. International Journal of Project Management, 33(6), 1317-1324. https://doi.org/10.1016/j.ijproman.2015.03.002

Wibowo, A., Permana, A., Kochendörfer, B., Kiong, R. T. L., Jacob, D., \& Neunzehn, D. (2012). Modeling contingent liabilities arising from government guarantees in Indonesian
BOT/PPP toll roads. Journal of Construction Engineering and Management, 138(12), 1403-1410.

https://doi.org/10.1061/(ASCE)CO.1943-7862.0000555

Wu, Y., Xu, C., Li, L., Wang, Y., Chen, K., \& Xu, R. (2018). A risk assessment framework of PPP waste-to-energy incineration projects in China under 2-dimension linguistic environment. Journal of Cleaner Production, 183, 602-617. https://doi.org/10.1016/j.jclepro.2018.02.077

Xiong, W., Zhang, X., \& Chen, H. (2015). Early-termination compensation in public-private partnership projects. Journal of Construction Engineering and Management, 142(4), 04015098. https://doi.org/10.1061/(ASCE)CO.1943-7862.0001084

$\mathrm{Xu}, \mathrm{F}$, \& Wang, H. (2018). Competitive-cooperative strategy based on altruistic behavior for dual-channel supply chains. Sustainability, 10(6), 2103. https://doi.org/10.3390/su10062103

Xu, Y., Chan, A. P., Xia, B., Qian, Q. K., Liu, Y., \& Peng, Y. (2015). Critical risk factors affecting the implementation of PPP waste-to-energy projects in China. Applied Energy, 158, 403411. https://doi.org/10.1016/j.apenergy.2015.08.043

Xu, Y., Yeung, J. F., \& Jiang, S. (2014). Determining appropriate government guarantees for concession contract: lessons learned from 10 PPP projects in China. International Journal of Strategic Property Management, 18(4), 356-367. https://doi.org/10.3846/1648715X.2014.971088

Zhang, S., Chan, A. P., Feng, Y., Duan, H., \& Ke, Y. (2016). Critical review on PPP research - a search from the Chinese and international journals. International Journal of Project Management, 34(4), 597-612.

https://doi.org/10.1016/j.ijproman.2016.02.008 